\title{
Fas promoter region gene polymorphism is associated with an increased risk for myocardial infarction
}

\author{
Hiroko Hanasaki ${ }^{1}$, Yukihiro Takemura ${ }^{1}$, Keisuke Fukuo $^{2}$, Mitsuru Ohishi ${ }^{1}$, Miyuki Onishi ${ }^{1}$, Osamu Yasuda ${ }^{1}$, \\ Tomohiro Katsuya ${ }^{1}$, Nobuhisa Awata ${ }^{3}$, Norihiro Kato ${ }^{4}$, Toshio Ogihara ${ }^{5}$ and Hiromi Rakugi ${ }^{1}$
}

A growing body of evidence has shown that Fas-mediated apoptosis is involved in atherosclerosis progression. Recent studies have revealed that a single nucleotide polymorphism (SNP) in the Fas promoter region ( $-670 \mathrm{G} / \mathrm{A})$ influences Fas expression. Here, we investigated whether -670G/A SNP influences the incidence of myocardial infarction (MI) by examining a comparison between MI patients $(n=154)$ and control subjects $(n=462)$ in a Japanese population. The allele frequency in each group was A $53.6 \% / G 46.4 \%$ in the MI patients, and A $43.9 \% / G 56.1 \%$ in the non-MI subjects $\left(\chi^{2}=8.6 ; P=0.003\right)$. The odds ratio was $2.62(95 \% \mathrm{Cl}: 1.43-4.88)$. As subjects with the -670AA genotype had a signal transducer and activator of transcription 1 (STAT1)-binding site in the Fas promoter region, STAT-1 activation by interferon- $\gamma$ may upregulate Fas expression in human vascular smooth muscle cells (VSMCs) of -670AA genotype subjects as described earlier. The Fas upregulation induces excess apoptosis to VSMCs, which leads to unstable plaque formation in atherosclerotic lesions and then potentially to plaque rupture, which can cause MI. Further investigation of hypertensive subjects revealed that the $-670 \mathrm{AA}$ genotype does not induce hypertension occurrence, supporting that this difference of MI occurrence between the -670AA genotype and the -670GG genotype may be because of plaque rupture followed by excess apoptosis of VSMCs in the atherosclerotic lesion. We conclude that the Fas promoter gene, SNP $(-670 \mathrm{G} / \mathrm{A})$, may be a risk factor of MI occurrence.

Hypertension Research (2009) 32, 261-264; doi:10.1038/hr.2009.2; published online 27 February 2009

Keywords: apoptosis; Fas; gene polymorphism; myocardial infarction; VSMCs

\section{INTRODUCTION}

In the last 50 years, it has become increasingly recognized that cardiovascular events, including myocardial infarction (MI), are socially crucial problems. Recent studies show that apoptosis plays an important role in atherogenesis. Specifically, the genesis of unstable plaques is deeply correlated with the apoptosis of vascular smooth muscle cells (VSMCs). ${ }^{1-4}$

Fas is a type I transmembrane protein, a member of the tumor necrosis factor/nerve growth factor receptor family, which can transduce the apoptotic signal into susceptible target cells through the binding of the Fas ligand (FasL) ${ }^{5-7}$ Experimental studies show that Fas is expressed on the surface of many cell types, such as VSMCs, and mediates apoptosis in these cells. ${ }^{4,5}$ Clinical studies have documented the relationship between the abnormal expression of Fas and immune disorders, such as the human autoimmune lymphoproliferative syndrome. ${ }^{8,9}$ Furthermore, mutations in the Fas gene, resulting in a defective Fas protein expression, have been reported in patients with the autoimmune lymphoproliferative syndrome, which is character- ized by generalized hypercellularity of secondary lymphoid organs. ${ }^{9-11}$ The Fas gene has been mapped to 10q24.1 and its genomic organization, including exons, introns and the promoter region, has been characterized. $^{12}$ One of the Fas promoter region polymorphisms is located at the -670 position from the transcription-starting site and results from an ATCCG (G/A) AA substitution. ${ }^{13}$ This polymorphism is located on a consensus sequence of the $\gamma$-activated sequence, which is a signal transducer and activator of transcription 1 (STAT1)-binding site. Thus, this $-670 \mathrm{G} / \mathrm{A}$ polymorphism may have a function in gene regulation. ${ }^{14}$ Recent studies have shown that interferon- $\gamma$ (IFN- $\gamma$ ) stimulation can upregulate Fas expression through STAT1 activation in monocytes isolated from -670AA genotype subjects but not from subjects with the $-670 \mathrm{GG}$ genotype. ${ }^{15,16}$ Although the Fas/FasL system is strongly correlated with cardiovascular diseases, ${ }^{17-23}$ there are few reports about the relationship between Fas gene polymorphisms and cardiovascular diseases in humans. Here we investigated whether the Fas gene polymorphism influences the development of MI and hypertension in humans.

\footnotetext{
${ }^{1}$ Department of Geriatric Medicine and Nephrology, Osaka University Graduate School of Medicine, Osaka, Japan; ${ }^{2}$ Department of Food Sciences and Nutrition, School of Human Environmental Sciences, Mukogawa Women's University, Hyogo, Japan; ${ }^{3}$ Department of Cardiology, Osaka Medical Center for Cancer and Cardiovascular Diseases, Osaka, Japan; ${ }^{4}$ Department of Gene Diagnostics and Therapeutics, Research Institute International Medical Center of Japan, Tokyo, Japan and ${ }^{5}$ Osaka General Medical Center, Osaka, Japan Correspondence: Dr Y Takemura, Department of Geriatric Medicine and Nephrology, Osaka University Graduate School of Medicine, 2-2 B6 Yamadaoka, Suita, Osaka 565-0871, Japan. 


\section{METHODS}

Study sample

1st panel. Patients with documented evidence of acute MI (acute MI) were identified from the discharge records of the Osaka Medical Center for Cancer and Cardiovascular Disease (Osaka City, Japan). We selected 154 patients (127 males and 27 females, aged 43-84 years) who developed acute MI and who received a percutaneous coronary intervention or coronary artery bypass graft. Age- and sex-matched controls $(n=462)$ without a history of MI were recruited from the outpatients of Osaka University Hospital.

2nd panel. Participants were recruited from the outpatients of private clinics belonging to the Amagasaki Medical Association. The definition of hypertension was as follows: (a) family history of hypertension, (b) systolic blood pressure $\geqslant 160 \mathrm{~mm} \mathrm{Hg}$ and/or diastolic blood pressure $\geqslant 100 \mathrm{~mm} \mathrm{Hg}$ or under chronic antihypertensive medication and (c) onset of hypertension at $<50$ years. Controls of panel 2 were defined as follows: (a) age $>50$ years old; (b) without family history of hypertension; and (c) systolic blood pressure $<130 \mathrm{~mm} \mathrm{Hg}$, diastolic blood pressure $<85 \mathrm{~mm} \mathrm{Hg}$ and no history of medication for hypertension.

The definition of hyperlipidemia was as follows: (a) fasting serum total cholesterol concentration $\geqslant 220 \mathrm{mg}$ per $100 \mathrm{ml}$ and (b) under chronic antihyperlipidemic medication. The definition of diabetes mellitus was as follows: (a) fasting blood sugar $\geqslant 140 \mathrm{mg}$ per $100 \mathrm{ml}$ and (b) under chronic antidiabetic medication.

All subjects in this study were Japanese, and gave signed informed consent to participate in the genetic analysis and in all other procedures associated with the study. The study protocol was approved by the Institutional Review Board (IRB) of Osaka University.

\section{Genotype determination using the TaqMan PCR method}

Genomic DNA was extracted from $200 \mu \mathrm{l}$ of buffy coat using a QIAamp DNA Blood Kit (QIAGEN KK, Tokyo, Japan). The G-to-A transversion at the nucleotide position -670 on the promoter region of Fas (Fas $-670 \mathrm{G} / \mathrm{A}$ ) was determined by the TaqMan PCR method. The Fas $-670 \mathrm{G} / \mathrm{A}$ polymorphism was detected using the following primers and probes: forward, $5^{\prime}$-CCCTATG

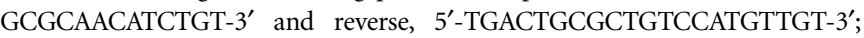
guanine base (G)-specific probe, 5'-FAM-TGGTTAACTGTCCATTCCAGgAA CGTCTGT-TAMRA-3'; and adenine base (A)-specific probe, 5' -VIC-TGGTTA ACTGTCCATTCCATaAACGTCTGT-TAMRA-3'. PCR proceeded using a GeneAmp PCR System 9700 thermal cycler (Applied Biosystems, Foster City, CA, USA). The PCR conditions were as follows: initial denaturation at $95^{\circ} \mathrm{C}$ for $10 \mathrm{~min}$, followed by $40 \mathrm{cycles}$ at $92^{\circ} \mathrm{C}$ for $15 \mathrm{~s}$ and at $60^{\circ} \mathrm{C}$ for $60 \mathrm{~s}$. The three genotypes were differentiated by analyzing the fluorescence levels of PCR products using an ABI PRISM 7900HT Sequence Detector (Applied Biosystems)

\section{Statistical analysis}

Associations between the polymorphisms and clinical variables were analyzed using the one-way analysis of variance. Differences in genotype or allele distribution were examined by the $\chi^{2}$ analysis. Multiple regression analysis assessed the contribution of the confounding factors. All numerical values are expressed as the mean \pm s.d. Significance is defined as $P<0.05$. All statistical analyses were conducted using JMP software version 3.1.5J for Windows (SAS Institute Inc., Cary, NC, USA).

\section{RESULTS}

Relationship between MI and Fas promoter gene polymorphism To determine whether the Fas promoter region polymorphism contributes to the incidence of MI, 154 patients with MI and 462 control subjects without MI were examined. The clinical characteristics of MI patients and non-MI control subjects are shown in Table 1. The former group had significantly higher number of patients with smoking habits, hypertension, diabetes mellitus and hyperlipidemia compared with the group consisting of control subjects.

Next, we checked the frequency of each genotype in the group with or without MI. As shown in Table 2, the frequency in the control
Table 1 Clinical characteristics of patients

\begin{tabular}{lccc}
\hline Variable & MI (+) & MI (-) & P-value \\
\hline$N$ & 154 & 462 & \\
Age (years) & $63.8 \pm 8.7$ & $63.7 \pm 8.7$ & NS \\
Gender (\% males) & $127(82 \%)$ & $381(82 \%)$ & NS \\
Smoking habits (\%) & $91(61 \%)$ & $176(38 \%)$ & $<0.0001$ \\
Hypertension (\%) & $78(52 \%)$ & $185(40 \%)$ & 0.008 \\
Diabetes mellitus (\%) & $53(36 \%)$ & $39(8 \%)$ & $<0.0001$ \\
Hyperlipidemia (\%) & $73(48 \%)$ & $104(22 \%)$ & $<0.0001$ \\
\hline
\end{tabular}

Abbreviations: MI, myocardial infarction; NS, nonsignificant.

Table 2 Frequency of Fas polymorphism

\begin{tabular}{lcr}
\hline Fas & $M I(+)$ & $M I(-)$ \\
Genotype & $n(\%)$ & $n(\%)$ \\
AA & & \\
GA & $45(29.2)$ & $83(18.0)$ \\
GG & $75(48.7)$ & $240(52.0)$ \\
\hline
\end{tabular}

Abbreviation: MI, myocardial infarction.

Additive model: $A A$ vs GA vs. GG, $P=0.008$

Dominant model: $A A+G A$ vs. GG, $\gamma^{2}=3.7, P=0.055$

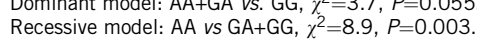

Table 3 Allele frequency and odds ratio

\begin{tabular}{lcc}
\hline Allele & $M I(+)$ & $M I(-)$ \\
\hline A & $n(\%)$ & $n(\%)$ \\
G & $165(53.6)$ & $406(43.9)$ \\
\hline
\end{tabular}

Abbreviations: $\mathrm{Cl}$, confidence interval; $\mathrm{MI}$, myocardial infarction.

$\chi^{2}=8.6, P=0.003$.

Odds ratio $=2.62(95 \% \mathrm{Cl} ; 1.43-4.88)$

group is $18.0 \%$ (AA), $52.0 \%(\mathrm{GA})$ and $30.1 \%(\mathrm{GG})$, whereas the MI group revealed 29.2\% (AA), 48.7\% (GA) and 22.1\% (GG) $(P=0.008$ AA vs. GA vs. GG (additive model), $\chi^{2}=3.7 ; P=0.055 \mathrm{AA}+\mathrm{GA} v$ s. GG (dominant model), $\chi^{2}=8.9 ; P=0.003$ AA vs. GA+GG (recessive model)). No significant difference of clinical characteristics (age, gender, hypertension, hyperlipidemia, diabetes mellitus and smoking) was observed with either genotype. Table 3 shows the allele frequency in each group (A: $53.6 \%$ and G: $46.4 \%$ in the MI patients, A: $43.9 \%$ and G: $56.1 \%$ in the non-MI subjects, $\chi^{2}=8.6 ; P=0.003$ ) and odds ratio (2.62, 95\% CI: 1.43-4.88). Then we selected these factors as the covariates of logistic analysis for MI occurrence and Fas -670G/A polymorphism (Table 4). There was an independent relationship between the genotype of $-670 \mathrm{G} / \mathrm{A}$ polymorphism and MI after adjusting covariates. These data indicate that the Fas promoter region -670G/A polymorphism is independently correlated to the occurrence of MI.

In addition, to investigate whether this contribution of the $-670 \mathrm{G} /$ A polymorphism is specific for MI occurrence, we examined 330 patients with hypertension and 219 control subjects without hypertension. Table 5 compares the clinical characteristics of these two groups. Age, gender and blood pressure were significantly higher in the hypertensive patients than in the control subjects. We checked the 
Table 4 Logistic analysis

\begin{tabular}{lcc}
\hline & Wald $\chi^{2}$ & P-value \\
\hline Diabetes mellitus & 42.9 & $<0.0001$ \\
Smoking habits & 29.9 & $<0.0001$ \\
Hyperlipidemia & 26.6 & $<0.0001$ \\
Hypertension & 17.2 & $<0.0001$ \\
A allele & 9.56 & 0.002 \\
Gender & 1.68 & 0.19 \\
Age (years) & 0.23 & 0.62 \\
\hline
\end{tabular}

Table 5 Clinical characteristics of patients

\begin{tabular}{lccc}
\hline Variable & $H T(+)$ & $H T(-)$ & P-value \\
\hline$N$ & 330 & 219 & \\
Age (years) & $60.0 \pm 10.8$ & $63.9 \pm 9.1$ & $<0.0001$ \\
Gender (\% males) & $158(48 \%)$ & $86(39 \%)$ & 0.047 \\
SBP (mm Hg) & $142 \pm 18.8$ & $117 \pm 10.7$ & $<0.0001$ \\
DBP (mm Hg) & $83.7 \pm 12.4$ & $69.6 \pm 8.1$ & $<0.0001$ \\
Smoking habits (\%) & $136(41 \%)$ & $76(35 \%)$ & NS \\
Diabetes mellitus (\%) & $60(18 \%)$ & $32(15 \%)$ & NS \\
Hyperlipidemia (\%) & $148(46 \%)$ & $82(38 \%)$ & NS \\
\hline
\end{tabular}

Abbreviations: DBP, diastolic blood pressure; HT, hypertension; NS, nonsignificant; SBP, systolic blood pressure.

Table 6 Frequency of Fas polymorphism

\begin{tabular}{lrr}
\hline & $H T(+)$ & $H T(-)$ \\
Fas & $n(\%)$ & $n(\%)$ \\
\hline Genotype & & \\
AA & $77(23.3)$ & $61(27.9)$ \\
GA & $157(47.6)$ & $110(50.2)$ \\
GG & $96(29.1)$ & $48(21.9)$
\end{tabular}

Abbreviation: $\mathrm{HT}$, hypertension.

Additive model: AA vs. GA vs. GG, $P=0.146$.

Dominant model: $\mathrm{AA}+\mathrm{GA}$ vs. GG, $\chi^{2}=3.5, P=0.061$.

Recessive model: $\mathrm{AA}$ vs. $\mathrm{GA}+\mathrm{GG}, \chi^{2}=1.4, P=0.232$.

frequency of each genotype in the group with or without hypertension. As shown in Table 6, the frequency in the control group is $27.9 \%$ (AA), $50.2 \%$ (GA) and $21.9 \%$ (GG), whereas the hypertensive group revealed $23.3 \%$ (AA), $47.6 \%$ (GA) and $29.1 \%$ (GG) $(P=0.146$ AA vs. GA vs. GG (additive model), $\chi^{2}=3.5 ; P=0.061 \mathrm{AA}+\mathrm{GA} v s$. GG (dominant model), $\chi^{2}=1.4 ; P=0.232$ AA $v s$. GA+GG (recessive model)). We then selected age and gender as the covariates of logistic analysis for hypertension occurrence and Fas -670G/A polymorphism. We found a weak but positive effect of the $-670 \mathrm{GG}$ genotype on hypertension $(P=0.044)$ after adjusting covariates. These data indicate that the effect of Fas promoter region -670G/A polymorphism on hypertension and $\mathrm{MI}$ is contradictory, supporting the notion that the occurrence of MI in the Fas -670AA subjects is not associated with hypertension.

\section{DISCUSSION}

In this study, we have shown that the G/A polymorphism in the Fas gene is associated with an increased occurrence of MI. These findings suggest that the A allele of G/A polymorphism in the promoter region ( $-670 \mathrm{G} / \mathrm{A})$ of the Fas gene may be a new genetic risk factor for MI.
Recent studies have shown that excess apoptosis of VSMCs promotes unstable plaque formation in atherosclerosis. ${ }^{24,25}$ In this study, we showed for the first time that a Fas promoter polymorphism may be a risk factor for MI occurrence. This may be dependent on the upregulation of Fas on VSMCs by IFN- $\gamma$ through STAT1 activation. ${ }^{15,16}$

Interferon- $\gamma$ is known to be a macrophage-activating factor produced by lymphocytes. ${ }^{26}$ Many reports have shown that IFN- $\gamma$ is associated with the incidence of cardiovascular disease in in vivo experiments. ${ }^{27-30}$ In atherosclerotic lesions, IFN- $\gamma$ is predominantly secreted from type 1 helper $\mathrm{T}$ cells. ${ }^{26}$ In addition, IFN- $\gamma$ can activate the JAK (Janus kinase)/STAT1 pathway, following STAT1 binding to the $\gamma$-activated sequence. ${ }^{31}$ Moreover, it is reported that the Fas receptor expression is regulated by STAT1, and the oligonucleotide with $-670 \mathrm{~A}$ in the Fas promoter region has a 3.5-fold higher binding ability to STAT1 than that with $-670 \mathrm{G} .{ }^{15,16}$ As Fas receptor upregulation in VSMCs induces Fas-mediated apoptosis and subsequent promotion of unstable plaques, ${ }^{24,32,33}$ this Fas promoter gene AA genotype can cause a two-fold increase in MI occurrence compared with the GG genotype.

To confirm whether this $-670 \mathrm{G} / \mathrm{A}$ polymorphism is uniquely associated with MI, we examined the contribution of Fas promoter region polymorphism to the incidence of hypertension. We observed that the Fas promoter region -670AA genotype does not induce hypertension. These data support that the Fas -670AA genotype is specifically associated with MI occurrence because of plaque rupture followed by the excess of VSMC apoptosis. After the adjustment of age and gender, however, the Fas -670GG genotype is weakly but significantly correlated to the incidence of hypertension $(P=0.044)$. In this regard, we have reported earlier that Fas signaling can activate endothelial nitric oxide synthase activation in endothelial cells, and can thereby regulate blood pressure. ${ }^{34}$ Endothelial cells are highly resistant to Fas-mediated apoptosis owing to FLIP (Fas-associated death domain-like interleukin-1 $\beta$-converting enzyme inhibitory protein) expression. Earlier we have shown that FasL stimulation can induce endothelial nitric oxide synthase activation in endothelial cells instead of apoptosis, and Fas-mutated lpr mice have higher blood pressure as a result of impaired endothelial function compared with wild-type mice. ${ }^{34}$ Thus, we predict that the $-670 \mathrm{AA}$ subjects may have lower blood pressure compared with -670GG subjects, because of the Fas receptor upregulation on intact endothelial cells after endothelial nitric oxide synthase activation with FasL stimulation.

In conclusion, we show that a polymorphism in the promoter region of the Fas gene (-670G/A) is associated with an increased risk for MI in Japanese subjects.

\section{Study limitations}

We predict that the upregulation of the Fas receptor on VSMCs induces excess VSMC apoptosis by the Fas-FasL system, after the generation of unstable plaques in the atherosclerotic lesion and promotion of plaque rupture. However, a limitation of this study was that we could not check plaque conditions in the atherosclerotic lesion of each genotype subjects. Further investigations are necessary to elucidate this association between the Fas -670G/A polymorphism and the formation of vulnerable atherosclerotic plaques.

\section{ACKNOWLEDGEMENTS}

The authors thank Ms Kazuko Iwasa and Ms Eriko Nagata for their continuous support to our investigations. The authors also thank Dr Tamar R Aprahamian (Boston University School of Medicine Department of Medicine-Renal Section) 
for her suggestions to this study. Source of funding: Yukihiro Takemura was supported by Research Fellowships of the Japan Society for the promotion of science for Young Scientists. This study was supported by a Grant-in-Aid for Scientific Research (H17-pharmaco-common-003) from the Japanese Ministry of Health, Labor, and Welfare, and Grants-in-Aid for Scientific Research (18590265, 18590811 and 19650188) from the Ministry of Education, Science, Sports and Culture of Japan, and by research grants from the Takeda Science Foundation, and the Japan Research Foundation for Clinical Pharmacology.

\section{CONFLICT OF INTEREST}

The authors declare no conflict of interest.

1 Saraste A, Pulkki K, Kallajoki M, Henriksen K, Parvinen M, Voipio-Pulkki LM. Apoptosis in human acute myocardial infarction. Circulation 1997; 95: 320-323.

2 Isner JM, Kearney M, Bortman S, Passeri J. Apoptosis in human atherosclerosis and restenosis. Circulation 1995; 91: 2703-2711.

3 Walsh K, Smith RC, Kim HS. Vascular cell apoptosis in remodeling, restenosis, and plaque rupture. Circ Res 2000; 87: 184-188.

4 Bjorkerud S, Bjorkerud B. Apoptosis is abundant in human atherosclerotic lesions, especially in inflammatory cells (macrophages and T cells), and may contribute to the accumulation of gruel and plaque instability. Am J Pathol 1996; 149: 367-380.

5 Nagata S. Apoptosis regulated by a death factor and its receptor: Fas ligand and Fas. Philos Trans R Soc Lond B Biol Sci 1994; 345: 281-287.

6 Nagata S. Apoptosis by death factor. Cell 1997; 88: 355-365.

7 Itoh N, Yonehara S, Ishii A, Yonehara M, Mizushima S, Sameshima M, Hase A, Seto Y, Nagata S. The polypeptide encoded by the cDNA for human cell surface antigen Fas can mediate apoptosis. Cell 1991; 66: 233-243.

8 Straus SE, Jaffe ES, Puck JM, Dale JK, Elkon KB, Rösen-Wolff A, Peters AM, Sneller MC, Hallahan CW, Wang J, Fischer RE, Jackson CM, Lin AY, Bäumler C, Siegert E, Marx A, Vaishnaw AK, Grodzicky T, Fleisher TA, Lenardo MJ. The development of lymphomas in families with autoimmune lymphoproliferative syndrome with germline Fas mutations and defective lymphocyte apoptosis. Blood 2001; 98: 194-200.

9 Vaishnaw AK, Orlinick JR, Chu JL, Krammer PH, Chao MV, Elkon KB. The molecular basis for apoptotic defects in patients with CD95 (Fas/Apo-1) mutations. J Clin Invest 1999; 103: 355-363.

10 Fisher GH, Rosenberg FJ, Straus SE, Dale JK, Middleton LA, Lin AY, Strober W, Lenardo MJ, Puck JM. Dominant interfering Fas gene mutations impair apoptosis in a human autoimmune lymphoproliferative syndrome. Cell 1995; 81: 935-946.

11 Rieux-Laucat F, Le Deist F, Hivroz C, Roberts IA, Debatin KM, Fischer A, de Villartay JP. Mutations in Fas associated with human lymphoproliferative syndrome and autoimmunity. Science 1995; 268: 1347-1349.

12 Inazawa J, Itoh N, Abe T, Nagata S. Assignment of the human Fas antigen gene (Fas) to 10q24.1. Genomics 1992; 14: 821-822.

13 Huang QR, Morris D, Manolios N. Identification and characterization of polymorphisms in the promoter region of the human Apo-1/Fas (CD95) gene. Mol Immunol 1997; 34: 577-582.

14 Cheng J, Liu C, Koopman WJ, Mountz JD. Characterization of human Fas gene. Exon/ intron organization and promoter region. J Immunol 1995; 154: 1239-1245.

15 Kanemitsu S, Ihara K, Saifddin A, Otsuka T, Takeuchi T, Nagayama J, Kuwano M, Hara T. A functional polymorphism in fas (CD95/APO-1) gene promoter associated with systemic lupus erythematosus. J Rheumatol 2002; 29: 1183-1188.
16 Farre L, Bittencourt AL, Silva-Santos G, Almeida A, Silva AC, Decanine D, Soares GM, Alcantara Jr LC, Van Dooren S, Galvão-Castro B, Vandamme AM, Van Weyenbergh J. Fas 670 promoter polymorphism is associated to susceptibility, clinical presentation, and survival in adult T cell leukemia. J Leukoc Biol 2008; 83: 220-222.

17 Sata M, Walsh K. Oxidized LDL activates fas-mediated endothelial cell apoptosis. J Clin Invest 1998; 102: 1682-1689.

18 Sata M, Walsh K. TNFalpha regulation of Fas ligand expression on the vascular endothelium modulates leukocyte extravasation. Nat Med 1998; 4: 415-420.

19 Suhara T, Fukuo K, Sugimoto T, Morimoto S, Nakahashi T, Hata S, Shimizu M, Ogihara T. Hydrogen peroxide induces up-regulation of Fas in human endothelial cells. J Immunol 1998; 160: 4042-4047.

20 Suhara T, Fukuo K, Yasuda O, Tsubakimoto M, Takemura Y, Kawamoto H, Yokoi T, Mogi M, Kaimoto T, Ogihara T. Homocysteine enhances endothelial apoptosis via upregulation of Fas-mediated pathways. Hypertension 2004; 43: 1208-1213.

21 Niinobu T, Fukuo K, Yasuda O, Tsubakimoto M, Mogi M, Nishimaki H, Morimoto S, Ogihara T. Negative feedback regulation of activated macrophages via Fas-mediated apoptosis. Am J Physiol Cell Physiol 2000; 279: C504-C509.

22 Shimizu M, Fukuo K, Nagata S, Suhara T, Okuro M, Fujii K, Higashino Y, Mogi M, Hatanaka Y, Ogihara T. Increased plasma levels of the soluble form of Fas ligand in patients with acute myocardial infarction and unstable angina pectoris. $J$ Am Coll Cardiol 2002; 39: 585-590.

23 Kotani N, Fukuo K, Yasuda O, Katuya T, Takemura Y, Kawamoto H, Yokoi T, Suzuki A, Ogihara T. Fas ligand mRNA levels of circulating leukocytes reflect endothelial dysfunction in hyperlipidemic but not in non-hyperlipidemic patients. Hypertens Res 2006; 29: 217-225.

24 Fukuo K, Nakahashi T, Nomura S, Hata S, Suhara T, Shimizu M, Tamatani M, Morimoto S, Kitamura Y, Ogihara T. Possible participation of Fas-mediated apoptosis in the mechanism of atherosclerosis. Gerontology 1997; 43(Suppl 1): 35-42.

25 Clarke MC, Figg N, Maguire JJ, Davenport AP, Goddard M, Littlewood TD, Bennett MR. Apoptosis of vascular smooth muscle cells induces features of plaque vulnerability in atherosclerosis. Nat Med 2006; 12: 1075-1080.

26 Leon ML, Zuckerman SH. Gamma interferon: a central mediator in atherosclerosis. Inflamm Res 2005; 54: 395-411.

27 Gupta S, Pablo AM, Jiang X, Wang N, Tall AR, Schindler C. IFN-gamma potentiates atherosclerosis in ApoE knock-out mice. J Clin Invest 1997; 99: 2752-2761.

28 Buono C, Come CE, Stavrakis G, Maguire GF, Connelly PW, Lichtman AH. Influence of interferon-gamma on the extent and phenotype of diet-induced atherosclerosis in the LDLR-deficient mouse. Arterioscler Thromb Vasc Biol 2003; 23: 454-460.

29 Whitman SC, Ravisankar P, Elam H, Daugherty A. Exogenous interferon-gamma enhances atherosclerosis in apolipoprotein E-I- mice. Am J Pathol 2000; 157: 1819-1824.

30 Koga M, Kai H, Yasukawa H, Kato S, Yamamoto T, Kawai Y, Kusaba K, Seki Y, Kai M, Egashira K, Kataoka Y, Imaizumi T. Postnatal blocking of interferon-gamma function prevented atherosclerotic plaque formation in apolipoprotein E-knockout mice. Hypertens Res 2007; 30: 259-267.

31 Boehm U, Klamp T, Groot M, Howard JC. Cellular responses to interferon-gamma. Annu Rev Immunol 1997; 15: 749-795.

32 Rosner D, Stoneman V, Littlewood T, McCarthy N, Figg N, Wang Y, Tellides G, Bennett $\mathrm{M}$. Interferon-gamma induces Fas trafficking and sensitization to apoptosis in vascular smooth muscle cells via a PI3K- and Akt-dependent mechanism. Am J Pathol 2006; 168: 2054-2063.

33 Kavurma MM, Tan NY, Bennett MR. Death receptors and their ligands in atherosclerosis. Arterioscler Thromb Vasc Biol 2008; 28: 1694-1702.

34 Takemura Y, Fukuo K, Yasuda O, Inoue T, Inomata N, Yokoi T, Kawamoto H, Suhara T, Ogihara T. Fas signaling induces Akt activation and upregulation of endothelial nitric oxide synthase expression. Hypertension 2004; 43: 880-884. 